\title{
NOTAS SOBRE LA PRUEBA EN EL PROCESO LABORAL A PARTIR DE LA REFORMA A LA LEY PROCESAL DEL TRABAJO, INSERCIÓN DEL EXPEDIENTE ELECTRONICO Y EMERGENCIA SANITARIA
}

\begin{abstract}
Carina Noemí Guevara'
Sumario: I- Introducción. II. Desarrollo. II.1. Desde "Acceso a la Justicia" al "Acceso a Justicia" en materia de prueba. II.2 Procedimiento Ordinario. Aspectos Probatorios II.2.A) Regulación actual. II.2.B) Expediente electrónico Disposiciones generales. Reglamento Expediente Electrónico. Disposiciones en materia de prueba. II.3.A) Reforma procesal laboral. Situación actual. II.3.B) Procedimiento Declarativo Abreviado. Aspectos probatorios. Regulación. Admisión. Diligenciamiento. II.3 C) Propuestas para agilizar el diligenciamiento de la prueba. II.4) Los procesos judiciales en la emergencia sanitaria. II.4.A) Generalidades. Fundamento legal. II.4.B) Etapas de la emergencia en el ámbito del Poder Judicial. Generalidades. II.4.C) Ofrecimiento. Diligenciamiento de la prueba. II.4.D) Otras alternativas de acceso a la justicia en la emergencia sanitaria. III. Reforma procesal. Conclusiones. IV. Reflexiones y propuestas. Emergencia sanitaria. V. Bibliografía.
\end{abstract}

Resumen: El presente comentario tiene como finalidad aportar elementos de reflexión y análisis y a partir de ello, generar propuestas en relación a algunos aspectos de la etapa probatoria a partir de la reforma a la Ley Procesal del Trabajo de la Provincia de Córdoba, la inserción del expediente electrónico y la situación actual de emergencia sanitaria.

Palabras clave: Prueba. Reforma. Expediente Electrónico. Emergencia Sanitaria. 


\section{I.- Introducción}

Como ya fue expuesto oportunamente ${ }^{2}$ y reafirmado por prestigiosos autores y especialistas del derecho del trabajo y del derecho procesal del trabajo, el aumento de la población, la litigiosidad, la escasez de recursos edilicios, técnicos y humanos, implicó reformar, la ley procesal vigente, para agilizar los procesos judiciales y dar respuesta eficaz al justiciable.

Ello fue punto de coincidencia en todos los actores que intervienen en el proceso laboral, lo cual llevó a los distintos sectores que intervienen en el mismo a realizar sus aportes y opiniones en aras de brindar su experiencia y conocimiento en el fuero del trabajo, para generar propuestas a tener en cuenta ante la eventual aplicación de la reforma de la ley.

Adelantamos que si bien analizamos la mayoría de los proyectos que se han llevado a cabo, nos referiremos expresamente al último que fue motivo de debate en la Legislatura de la Provincia de Córdoba y que fuera convertido en ley³, con sucesivas prórrogas de su aplicación.

Volvimos a repasar aspectos de los análisis efectuados por los Jueces de Conciliación y Camaristas, dictamen del Colegio de Abogados de Córdoba, posiciones doctrinarias, ponencias de los Dres. Seco y Arese, en relación a la Reforma Procesal.

Asimismo se relevaron los distintos trabajos, disertaciones, debates, etc relacionados a la temática tomando en especial consideración los llevados a cabo en el ámbito del Instituto de Investigaciones Jurídicas de la UBP.

Sin embargo, como ya hemos señalado los puntos generales de la reforma procesal, precisaremos el análisis de la regulación propuesta en relación a ciertos aspectos de la prueba y al trámite de la admisión y diligenciamiento de la misma a partir de la inserción del expediente electrónico, en especial teniendo en cuenta la situación actual de emergencia sanitaria.

Ello es así a partir de las modificaciones necesariamente impuestas en los distintos trámites procesales, entre la exposición oral de los principales tópicos del presente trabajo - 13/5/19- y la actualidad a partir de la emergencia sanitaria dispuesta por el Covid 19.

Se hará una breve referencia al trámite de la prueba en el expediente electrónico y del expediente papel, procurando, demostrar y precisar la importancia y necesidad de la implementación de la tecnología en todo proceso judicial, en la transición y aplicación de la reforma procesal, y algunas ventajas y desventajas visualizadas desde su aplicación hasta el momento.

Todo ello con el fin de aportar elementos e ideas para que la aplicación de la legislación procesal brinde tutela efectiva al trabajador, para transitar el proceso judicial garantizando la protección integral de los trabajadores contenidos en normas constitucionales e internacionales, sustantivas y procesales, procurando respuestas eficaces y ágiles, en concordancia con los principios del derecho del trabajo, del derecho procesal del trabajo,

2 GUEVARA, Carina Noemí, "Análisis de los principales aspectos de la conciliación y la prueba en la reforma a la Ley Procesal del Trabajo de Córdoba”, en Revista de Estudio de Derecho Laboral y Derecho Procesal Laboral, Sala de Derecho Laboral y Derecho Procesal Laboral, Instituto de Investigación en Ciencias Jurídicas Universidad Blas Pascal, p.53, Córdoba, Argentina, Año 1, Nro. 1, noviembre 2019 // ISSN Versión online: XXXX-XXXX. 
con aplicación de los principios de gratuidad, igualdad de trato y no discriminación ${ }^{4}$, enfatizando los principios pro homine y de progresividad de los derechos de los trabajadores, dado que son sujetos de preferente tutela constitucional.

Creemos que es responsabilidad de todos quienes actuamos el derecho del trabajo y el derecho procesal del trabajo procurar generar los mecanismos que permitan alcanzar dichos objetivos con la aplicación de la nueva legislación y recursos tecnológicos.

\section{Desarrollo}

\section{II.1. Desde "Acceso a la Justicia" al "Acceso a Justicia" en materia de prueba.}

Como hicimos referencia en el trabajo en el cual puntualizamos los aspectos conciliatorios de la reforma "uno de los principales pilares de la reforma procesal laboral es la necesidad de contemplar el acceso a la justicia y agilizar los procesos judiciales."

Es decir, creemos que la intención del legislador en toda reforma legislativa es adecuar el derecho a los cambios sociales, remarcándose la necesidad de priorizar el acceso a justicia del justiciable en todas las etapas del proceso y con más razón en la producción y diligenciamiento de la prueba de manera eficaz.

Como referenciáramos, a través de la reformulación del concepto "acceso a justicia", se pretende optimizar el servicio de justicia, lo cual conlleva un trabajo interdisciplinario en materia de prueba.

Como afirmó la Dra. Higthon, dicho concepto es amplio ${ }^{5}$, que implica brindar otras gamas de soluciones que no sólo es la línea clásica de dictar la sentencia y si bien los jueces tienen dicha responsabilidad como principal función, al conformar un Poder del Estado, también tienen la obligación de ofrecer un menú más amplio que el dictado de la sentencia ${ }^{6}$, es decir que se requiere que los mismos en forma práctica y dinámica garanticen el acceso a la justicia y en la materia que nos ocupe procuren la producción y diligenciamiento de la prueba.

Su objetivo es promover e incentivar el acceso a justicia a través de métodos alternativos de resolución de conflictos, disminuir la litigiosidad judicial y optimizar el servicio de justicia en todo el territorio argentino, con el fin principal de dar una adecuada respuesta a los nuevos desafíos que enfrenta la Justicia de nuestro tiempo ${ }^{7}$.

En general se debe procurar que la estructura judicial facilite el acceso a la justicia con especial contención del justiciable vulnerable, lo cual condice con lo analizado, cuando afirma que se ha venido definiendo que el derecho de acceso a la justicia, en sentido amplio integra el concepto de jus cogens ${ }^{8}$.

\footnotetext{
4 FERREYRA DE DE LA RÚA, Angelina- RODRÍGUEZ JUÁREZ, Manuel (directores), Tribunal Superior de Justicia de Córdoba. Máximos precedentes, autoras GUEVARA, Carina Noemí y MARTíNEZ, María Soledad, "Precisiones en torno a los principios de gratuidad y de igualdad de trato y no discriminación en el Derecho del Trabajo", Editorial La Ley, Buenos Aires, 2013.

5 Dicho concepto ha sido elaborado y es propiciado por la Ministra de la CSJN Dra. Elena Highton de Nolasco, en el marco de la Comisión Nacional de Acceso a Justicia, quien está a cargo de la misma desde su creación en el año 2007. Es por ello que en oportunidad de presentar propuestas que integran el Plan Nacional de Reformas para el Poder Judicial elaborado por el máximo tribunal, para mejorar el acceso a justicia de la ciudadanía, el cual surgió del debate de jueces convocado por la Corte Suprema en marzo de 2018.

6 Conferencia: "Los jueces estamos para garantizar el acceso a justicia" del 14/6/10, en https://www.cij.gov.ar/nota-4501-Highton---Los-jueces-estamospara-garantizar-acceso-a-justicia-.html

7 https://www.cij.gov.ar/nota-32632-Highton-present--nuevos-proyectos-de-acceso-a-justicia.html

8 ARESE, César, Derechos Humanos Laborales. Teoría y Práctica de un nuevo derecho del trabajo, Editorial Rubinzal - Culzoni, 2014, Santa Fe.
} 
Por otro lado, como afirma Dr. Seco", "emerge el Juzgado del Trabajo que es una figura nueva, con un titular juez unipersonal y con una competencia funcional mayor a la de los Jueces de Conciliación".

Del análisis de los autores citados surge que principalmente la reforma procesal tiende a la abreviación de los plazos procesales y a la resolución con agilidad y en tiempos razonables, especialmente en la etapa probatoria, de las causas de menor complejidad, mediante la incorporación del juicio declarativo abreviado, ampliando la competencia funcional de los Jueces de Conciliación y del Trabajo.

Así en definitiva se pretende evitar la excesiva litigiosidad y que los procesos judiciales sean largos y costosos, sobre todo si se recurren y llegan a la CSJN ${ }^{10}$.

\section{II.2 Procedimiento Ordinario. Aspectos Probatorios. II.2.A) Regulación actual.}

En materia de prueba la ley procesal vigente regula el tema en el art.39 que dispone la inversión de la carga de la prueba y en el art.52 que determina que las partes deben ofrecer prueba en el término perentorio de seis días de finalizada la audiencia de conciliación.

Se diligencian las pruebas escritas ante el Juez de Conciliación y las orales ante la Sala de la Cámara del Trabajo.

Sin pretender analizar la regulación de cada medio probatorio por exceder el objeto del presente trabajo, sólo precisamos que para recepcionar las audiencias de reconocimiento y exhibición se aplican los arts. 39 del CPT, 55 de la LCT y 249 y cc del CPCC. Asimismo para diligenciar medios probatorios que no cuenten con regulación expresa en la LPT se debe aplicar, por remisión del art.114 de la LPT, el CPCC.

En relación al diligenciamiento de la prueba informativa se debe tener presente que la misma se regula a través del juego armónico de los artículos 15 (impulso procesal de oficio y colaboración de los letrados en el diligenciamiento de pruebas) y 53 de la de la ley 7987 (el Juez de Conciliación procederá a su recepción dentro de un término no mayor a noventa días) ${ }^{11}$, como así también arts. $181^{\circ}$ ley 5805, 317, 322 y c.c del CPCC.

\footnotetext{
9 SECO, Ricardo Francisco, "El proyecto de Reforma Procesal en la Provincia de Córdoba", XXII Congreso Nacional de Derecho del Trabajo y de la Seguridad Social, 4 y 5 de octubre de 2018, Santa Fe. Módulo "Reformas Procesales en los ámbitos provinciales y en la Ciudad Autónoma de Buenos Aires". 10 SECO, Ricardo Francisco Seco (director), ¿Es obligatorio el seguimiento de los fallos de la CSJN?, investigación UBP, año 2018.

11 EXPEDIENTE PAPEL: 8755972. Córdoba, 28 de noviembre de 2019. Ténganse por ofrecidas en tiempo y forma las pruebas de las partes; admítanse A LAS DEL ACTOR:....... A LAS DE LA DEMANDADA:......- INFORMATIVA: AFIP y Escribanía Registro $\mathrm{N}^{\circ}$.....: Ofíciese. Anses: atento lo dispuesto por el decreto nacional $\mathrm{N}^{\circ}$ 507/93, ratificado por el art. 22 de la ley 24.447 y la resolución Anses 112/95, a los fines de recabar la información solicitada ofíciese a la AFIP......... Atento el deber impuesto a los letrados por el art. 15 de la ley 7987, art. $181^{\circ}$ párrafo, y 53 de la LPT, emplácese a las partes para que libren, suscriban, y diligencien los oficios correspondientes a sus pruebas informativas y arbitren los medios conducentes a los fines de lograr la oportuna respuesta de los entes oficiados, debiendo acreditar su diligenciamiento mediante presentación electrónica con archivo adjunto de los oficios escaneados, debiendo acreditar la presentación de los respectivos oficios en el término de veinte días y tener diligenciadas dichas pruebas en definitiva en el término del art. 53 LPT, y en el caso de no haberse logrado deberá acreditar en el término mencionado su diligencia en la producción bajo apercibimiento de tener dichas pruebas por no producidas.- Notifíquese bajo apercibimiento de ley......... Fdo. digitalmente por QUIROGA - Juez- GARCIA CASTRILLON -secretario EXPEDIENTE ELECTRÓNICO: 8756304.Córdoba, 13 de diciembre de 2019. Por ofrecidas en tiempo y forma las pruebas de las partes. Admítase. PRUEBA DE LA PARTE ACTORA..... PRUEBA DE LA PARTE DEMANDADA....III. INFORMATIVA: EPEC: ofíciese...... Atento el deber impuesto a los letrados por el art. 15 de la ley 7987, en concordancia con el art. 322 primer pár. del CPCC -de aplicación supletoria según el art. 114 de la ley foral-, las atribuciones conferidas por el art. 18 primer pár. de la ley 5805 y lo establecido en el art. 53 y cc. de la LPT, se hace saber a las partes que deben confeccionar, suscribir y presentar -ante persona autorizada para su recepción- los oficios correspondientes a su prueba informativa, la que deberá estar diligenciada en el término de noventa días -establecido por el citado art. 53, bajo apercibimiento de tenerlas por no producidas. Emplácese a las partes para que en el plazo de treinta días acompañen - para su agregación en autos- las constancias de presentación respectivas con fecha, firma y sello de recepción, bajo apercibimiento de tener la prueba informativa de que se trata por no producida.Asimismo emplácese a las empresas y/u organismos oficiados para que en el plazo de diez días contesten los informes requeridos -únicamente respecto de actos o hechos que resulten de la documentación, archivos o registros contables que obren en su
} 
Sin embargo la reforma procesal mencionada hace un agregado al art. 53 de la LPT y dispone que: "....Juez podrá sustituir de oficio medios probatorios cuando existieren notoriamente otros que permitan la acreditación de los hechos con mayor celeridad y eficacia.." De este modo, se amplían las facultades del juez como director del proceso, aunque en la actualidad está suspendida la aplicación de la misma como se aclarará infra.

\section{II.2.B) Expediente electrónico. Disposiciones generales.}

Conforme lo dispuesto por el art. 166 inc. $2^{\circ}$ de la Constitución de la Provincia de Córdoba, art. 12 inc. $1^{\circ}$ de la Ley Orgánica del Poder Judicial N8435, el Tribunal Superior de Justicia mediante el Acuerdo Reglamentario 1582, serie "A", del 21/8/19, del Tribunal Superior de Justicia, se dispuso aprobar el Reglamento General para el Expediente Judicial Electrónico y sus correspondientes Políticas de Seguridad, adjuntado como anexo del mismo ${ }^{12}$.

Se resalta que dicho Reglamento continuará siendo revisado durante el plazo que dure la ejecución del Plan de Despliegue dispuesto.

Se faculta a la Presidencia del Tribunal Superior de Justicia, con el asesoramiento del Consejo de Coordinación SAC y del Área TIC, para dictar las normas generales y obligatorias que requiera la correcta aplicación o desarrollo del mismo, incluidas las que aprueben los cronogramas de avance del plan de despliegue, y las necesarias para regular las situaciones no previstas expresamente.

\section{Reglamento Expediente Electrónico. Disposiciones en materia de prueba}

Artículo 19. Prueba documental

“En todos los casos, luego de adjuntar documental digitalizada, los documentos originales deberán presentarse para su compulsa. El documento original quedará en poder del tribunal mientras éste no resuelva de manera fundada su restitución. Cuando, por las características propias de la prueba documental, no fuera posible su digitalización o cuando los documentos excedan el tamaño máximo admitido en la plataforma de presentación electrónica, podrán presentarse directamente ante la oficina judicial correspondiente, para la adopción de las medidas de resguardo pertinentes."

\section{Artículo 24. Presentación de escritos}

“La presentación de escritos deberá efectuarse a través de la plataforma de presentación electrónica de escritos, a los que podrán adjuntarse documentos en formato digital en la medida en que sea factible, según los formatos y tamaños admitidos por la plataforma. De no ser posible, se procederá conforme lo establecido por el último párrafo del artículo 19 del presente Reglamento General. Como únicas excepciones, los órganos judiciales

poder (art. 317 del CPCC)-, bajo los apercibimientos establecidos en los arts. 321 del CPCC y 804 del CCC, según corresponda. Transcríbase la normativa citada en los respectivos oficios.... FDO digitalmente por MORENO DOUGLAS PRICE Santiago- Juez -PELLITTERI Andrea - Secretaria

12 Acuerdo Reglamentario 1582, serie "A", del 21/8/19, en sus considerandos dispone: “... I. Que el artículo 14 de la Ley N ${ }^{\circ} 10.177$, faculta a este Tribunal Superior de Justicia, a reglamentar el uso del expediente electrónico y la firma electrónica y/o digital, así como disponer su gradual implementación. II. Que el Área de Tecnologías de la Información y Telecomunicaciones informa que las actuales condiciones alcanzadas, permiten instrumentar el inicio de actividades para la ejecución del Plan de Despliegue del expediente judicial electrónico en toda la provincia en un plazo aproximado de doce (12) meses. III. Que, en el marco del proceso continuo de mejora en el funcionamiento del servicio de administración de justicia, el Poder Judicial de Córdoba viene realizando de manera sistemática y progresiva, un incremento de las funcionalidades internas y externas del SAC para optimizar el sistema de gestión y la tramitación remota de las causas judiciales por parte de los abogados y otros auxiliares de justicia. IV. Que la digitalización de datos, documentos y procedimientos, así como la instauración de las firmas digital y electrónica, cuya validez jurídica encuentra sustento en las Leyes Nacionales $\mathrm{N}^{\circ} 25.506$ (Reglamentada mediante Decreto No 182/2019, del Poder Ejecutivo Nacional del 11-03-2019 BO 12/03/2019), y No 26.685, y Leyes Provinciales No 9.401 y $\mathrm{N}^{\circ} 10.177$, constituyen la infraestructura tecnológica necesaria para alcanzar los objetivos de facilitar el acceso de los ciudadanos a la información y servicios públicos, en forma segura a través de internet, así como procurar la gradual despapelización y mayor eficiencia del Estado en la gestión de sus recursos y la prestación de sus servicios..... 
recibirán escritos en soporte papel, en los siguientes casos: a) Presentaciones por parte de auxiliares de justicia o terceros, que no hayan celebrado convenio con el Tribunal Superior de Justicia que los habilite a realizar las presentaciones en forma electrónica."

Artículo 29. Expediente como prueba

"Cuando las constancias de un expediente electrónico deban examinarse en el trámite de otro, se solicitará la puesta a disposición temporal para su visualización con idénticas previsiones de la puesta a disposición de usuarios habilitados, sin remisión."

En el art 32 se regula la emisión de oficios por los órganos judiciales, en el art 33 los oficios diligenciados por abogados, en el art 34 el mecanismo de tramitación de los organismos auxiliares, diligenciamiento de oficios y exhortos ley $N^{\circ} 22.172$, etc.

\section{II.3.A) Reforma procesal laboral. Situación actual.}

Creemos necesario repasar la situación actual de la ley que impulsó la reforma procesal laboral. En tal sentido la original ley 10.596 que fuera publicada el 28/12/18, en su art.17 dispuso que entraría en vigencia a los seis meses de su publicación, es decir, el 28/6/19. Sin embargo fue prorrogada por ley 10.640 del 28/6/19 que dispuso la suspensión de la entrada en vigencia de la ley № 10.596, de modificación del Código Procesal de Trabajo, por el término de ciento ochenta (180) días, es decir hasta el 28/1/20. Mediante la ley 10.676, publicada el 27/12/19, se modificó el art. 17 de la ley 10.596 y dispuso que entre en vigencia el 1/4/20.

Asimismo en el marco del receso judicial extraordinario, dispuesto en virtud de la emergencia sanitaria que se transita en la actualidad a la cual nos referiremos infra, el Tribunal Superior de Justicia, mediante resolución de Presidencia No 14 del 26/3/20, consideró la inconveniencia de poner en funcionamiento el nuevo modelo procesal, por lo cual ordenó prorrogar la entrada en vigencia de la ley $N^{\circ} 10.596$ (modificada por ley $N^{\circ} 10.676$ ) por el término de tres meses, con lo cual empezaría a regir el 1/7/2013.

Dada la continuidad de la emergencia sanitaria, y en razón de que las distintas modalidades de prestación adoptadas - receso judicial extraordinario, servicio de justicia en la emergencia y prestación presencial reducida- han impedido realizar la coordinación y puesta a punto final de las acciones operativas y la interacción de los distintos agentes para la aplicación de los protocolos previstos, viéndose interrumpido en la etapa final, el trabajo de organización diagramado, previo a la entrada en vigencia de la mencionada ley y que en este contexto, es necesario prever los nuevos escenarios que eventualmente pueden presentarse con motivo de la persistencia de la emergencia sanitaria.

Es por ello, mediante Ac. 1634 Serie A del 25/6/20, el Tribunal Superior de Justicia resolvió prorrogar la entrada en vigencia de la ley $N^{\circ} 10.596$ prevista para el $1^{\circ}$ de julio del corriente año -conforme lo dispuesto por ley $N^{\circ} 10.676$ y resolución de Presidencia del TSJ Nº 14/2020- por el término de tres meses, por lo que comenzará a regir desde del $1 / 10 / 20^{14}$.

\footnotetext{
13 Res. 14 del 26/3/20, "Y CONSIDERANDO... IV. Que, en dicho Fuero, el receso judicial extraordinario implica, en la práctica, la suspensión y reprogramación de innumerables audiencias, por lo que la reanudación de la actividad judicial va a generar una sobrecarga de trabajo de los juzgados... “.

14 Ac. 1634 Serie A del 25/6/20, "Y CONSIDERANDO: ... Concretamente en el fuero laboral, la entrada en vigencia de la Ley Provincial No 10.596 , se encontraba prevista para el 1 de abril del corriente año, conforme lo dispuesto por Ley $\mathrm{N}^{\circ} 10.676$; es decir en la época en que la emergencia sanitaria irrumpía en el contexto nacional y provincial, con ribetes desconocidos y las disposiciones de aislamiento adoptadas por las autoridades competentes resultaban de lo más estrictas..."
} 


\section{II.3.B) Procedimiento Declarativo Abreviado. Aspectos probatorios. Regulación. Admisión. Diligenciamiento.}

Como ya fue señalado, en relación a la admisión y diligenciamiento de la prueba nos detendremos en el art 83 quinquies el cual dispone “...cuando de la contestación surgieran cuestiones controvertidas de las que a criterio del juez deba producirse prueba, el tribunal podrá disponer la producción de la misma, a cuyo fin pasará a un cuarto intermedio, debiendo fijar fecha y hora para la continuación de la audiencia en un plazo máximo de sesenta días, y se intimará a las partes para que dentro de ese plazo diligencien toda su prueba, bajo apercibimiento de tenerla por no producida. Cuando sea posible y pertinente dispondrá que las pruebas se realicen digitalmente."

Consideramos que dicha regulación permitirá acortar los plazos del procedimiento y más aun utilizando los recursos digitales y tecnológicos.

Resaltamos las facultades otorgadas al Juez de Conciliación y del Trabajo, reguladas en el art 83 sexies, de sustituir de oficio medios probatorios cuando existan otros que permitan acreditar los hechos con mayor celeridad y eficacia y de disponer la inadmisibilidad de las pruebas que sean manifiestamente improcedentes, inconducentes, sobreabundantes, dilatorias, prohibidas por la ley o que la cuestión sometida a prueba sea de puro derecho.

\section{II.3 C) Propuestas para agilizar el diligenciamiento de la prueba.}

Se debería reglamentar la facultad otorgada por la ley al Juez de Conciliación como director del proceso evitando la admisión y producción de pruebas que sean inconducentes para la causa.

Se debe avanzar en lograr convenios con instituciones públicas y privadas para que las pruebas informativas sean respondidas por mail o por vía electrónica.

También se debe procurar agilizar el procedimiento aplicando los principios procesales de celeridad, concentración y economía procesal.

\section{II.4) Los procesos judiciales en la emergencia sanitaria. \\ II.4.A) Generalidades. Fundamento legal.}

La pandemia producida por el virus del COVID 19 (coronavirus) se enmarcó en la emergencia sanitaria establecida por ley $N^{\circ} 27.541$, luego ampliada por decreto de necesidad y urgencia (DNU) No 260 del 12/3/2020.

En tal sentido cabe remarcar el interesante análisis hecho por Duilio Moreno Del Papa en un reciente trabajo sobre el marco normativo y el contexto en que fue dispuesta a nivel nacional la emergencia sanitaria. Suma el fundamento constitucional como también lo funda con la jurisprudencia de la cual surge que "El Estado...tiene el deber de realizar prestaciones positivas" y que "...a partir de lo dispuesto en los tratados internacionales que tienen jerarquía constitucional (art. 75 inc. 22, Ley Suprema), ha reafirmado en recientes pronunciamientos el derecho a la preservación de la salud-comprendido dentro del derecho a la vida- y ha destacado la obligación impostergable que tiene la autoridad pública de garantizar ese derecho con acciones positivas...". "La acción positiva a la cual puede recurrir el Estado para preservar la salud, ante la ausencia de medicación idónea que permita evitar la propagación y la afectación de la salud, es el aislamiento social al 
que se ha recurrido." De este modo se hace prevalecer el interés general por sobre el individual, brindando tutela efectiva a toda la comunidad. ${ }^{15}$

La Provincia de Córdoba adhirió a ella por la ley N 10.690 del 18/3/2020, lo que implicó reacomodarse a dicha situación en todas las aristas.

De esta forma se resolvió mantener la restricción de la circulación de la mayoría de la población, para evitar los efectos que el contagio masivo podría significar para el sistema sanitario argentino.

En tal sentido el Poder Judicial de la Provincia de Córdoba estableció regulaciones en su función de Poder independiente y en el ejercicio de sus facultades de superintendencia y de administración de Justicia otorgadas por la Constitución Provincial y la Ley Orgánica del Poder Judicial para organizar su estructura y continuar con la prestación del servicio de justicia. Procuró viabilizar distintas resoluciones y protocolos para procurar la prestación del servicio de justicia en la emergencia sanitaria ${ }^{16}$.

\section{II.4.B) Etapas de la emergencia en el ámbito del Poder Judicial. generalidades.}

-Receso judicial extraordinario por razones sanitarias: (caracterizado en forma similar a la feria judicial, establecido mediante Acuerdo Reglamentario $N^{\circ} 1620$ serie "A" del TSJ de fecha 16/3/2020.

Dicho período se extendió entre el 17/3/2020 y el 26/4/2020, en dicho período y a partir del 8/4 se fueron emitiendo Protocolos de actuación que fueron habilitando actos procesales.

Las principales características de esta etapa es que las cuestiones urgentes (art. 44 del C.P.C.C) fueron encauzadas mediante "presentaciones judiciales de carácter urgente" dirigidas a la casilla oficial de correo electrónico de cada Juzgado.

En relación a las presentaciones en expedientes papel, se presentaron como "Solicita habilitación de día y hora en expediente papel".

Respecto al trámite de expediente electrónico, se asignaban a la dependencia de radicación del mismo. Las actuaciones registradas, luego de finalizado el receso serán incorporadas a los expedientes papel ya existentes.

Los plazos se suspendieron y se dispuso el cese de la prestación del servicio de Justicia de modo presencial.

- Servicio de justicia en la emergencia por razones sanitarias: entre el 26/4/2020 y el 7/6/2020, caracterizada por la prestación del servicio en forma remota.

Se aprueba entre otros el Protocolo de Actuación de los Juzgados de Conciliación mediante la modalidad de teletrabajo (AR 1623 Anexo III).

15 MORENO DEL PAPA, Duilio, "Cuarentena. Aislamiento Social Obligatorio: Marco Normativo en Argentina y la legalidad de sus disposiciones", junio/20.

16 Ver https://www.justiciacordoba.gob.ar/eticajudicial/paginas/trib_acuerdos.htm. 
Coincidimos con la Lic. Pascetti ${ }^{17}$ al expresar que "la crisis del coronavirus ha tocado de lleno a las organizaciones y personas. Los modos de trabajar, no escapan a este fenómeno, y las diferentes profesiones e instituciones se han visto obligadas a forzar el teletrabajo, salvo casos excepcionales...".

Este nuevo formato desafía a las personas e instituciones a adaptar sus modos de trabajo, sus espacios y sus formas de vincularse con sus equipos y colaboradores, a través de los medios que ofrece la tecnología mediante videoconferencias, reuniones virtuales, etc. que son esenciales en esta situación de emergencia.

Si bien no es objeto de este trabajo, no podemos dejar de mencionar el proyecto de ley sobre teletrabajo que ya fue debatida en Diputados, siendo tratada actualmente en el Senado, coincidimos con Mirna Lozano Bosch ${ }^{18}$, quien mediante varias entrevistas explicó que dicho proyecto va a incorporar a la Ley de Contrato de Trabajo la modalidad del "contrato de teletrabajo", con un concepto amplio, el cual se caracteriza en forma parcial o total mediante la prestación del trabajo con el uso de la tecnología.

Es muy interesante puntualizar la propuesta de la Dra. Lozano Bosch al manifestar que dicho proyecto regula cuestiones generales, algunas actividades, pero serán los convenios colectivos de trabajo los que ajustarán detalles y/o otorgarán especificidad a la actividad.

También agrega que en general otras cuestiones que trata el proyecto que la ley será aplicable a los 90 días de finalizado el ASPO es decir, en contexto de normalidad. Son varios los puntos en debate, no es la intención agotar los mismos, sino establecer cuestiones relacionadas a los montos de compensación, pago de conectividad, horarios, tareas fuera de horario, como afirma la autora cordobesa, se proyecta pactar la jornada por objetivos por escrito, específicos, lo cual puede llevar a la precarización del trabajador. También en relación a la jornada cuando se tiene gente a cargo y/o cuidados, derecho a horarios compatibles y a interrumpir la jornada (coordinando equipos) y hacer valer el derecho a la desconexión.

Como así también el tema de la reversibilidad del contrato, aclarando que si nació como teletrabajo puede ser reversible y volver a la presencialidad por la evaluación del teletrabajador. Todas estas cuestiones implican estar en sintonía con el resto del mundo en el cual ya está regulado el teletrabajo en varios países.

En relación a los plazos, el Protocolo que se analizó ut-supra estableció días inhábiles a los fines procesales y administrativos, salvo los actos válidamente cumplidos - cuando el Tribunal lo habilitara de manera expresa.

-Prestación del servicio de justicia de manera presencial administrada o semipresencial: a partir del 8/6/2020 hasta la actualidad, dispuesta mediante Ac. AR 1629, del 6/6/20 del Tribunal Superior de Justicia caracterizada por retomar la actividad en forma controlada.

17 PASCETTI, Eugenia, en el ámbito del Curso de Capacitación en el Aula Virtual del Centro Núñez, Poder Judicial, junio/julio 2020, cuyos ejes son: Contexto global, desafíos actuales y futuros en torno al homeoffice, claves para gestionar equipos remotos, hacks para autogestionar las rutinas laborales en el ámbito del teletrabajo y trabajo remoto y nuevos hábitos y retos de homeoffice. Ver http://campusvirtualcn.justiciacordoba.gob.ar/.

18 LOZANO BOSCH, Mirna, “Dictamen que pretende regular el teletrabajo”, entrevista radial con Ricardo Césari del 23/6/20. 
Se establecieron medidas de bioseguridad, ingreso y circulación, nómina de empleados, etc.

También se establecieron turnos presenciales con recaudos, se habilitó turnero telefónico y digital, la presentación remota de escritos en expedientes papel "enviar nuevo escrito en expediente papel", dejando sin efecto, solicitud de habilitación de día y hora.

Se reanudaron los plazos procesales a partir del 16/6/20 y en la semana pasada se establecieron nuevas funcionalidades para martilleros y se ampliaron turneros en la oficina de ujieres y notificadores.

\section{II.4.C) Ofrecimiento. Diligenciamiento de la prueba.}

El Protocolo de Actuación de los Juzgados de Conciliación dispuso la modalidad de teletrabajo (AR 1623 Anexo III).

Los principales mecanismos para la tramitación de la prueba son: las presentaciones se hacen de manera electrónica mediante el SAC y si es un expediente papel lo debe presentar conforme al AR 1629 Anexo 2 - Presentación remota de escritos en expedientes papel.

Contestado el traslado o vencido el plazo sin evacuarlo, se certifica y se dispone la apertura de la causa a prueba, lo que se notifica de manera electrónica.

En relación al ofrecimiento de la prueba documental: se debe adjuntar digitalizada, si los archivos son grandes (se tienen que comprimir y/o dividir la presentación). Se omite el requisito de compulsa de la documentación adjuntada (se admite como declaración jurada del presentante la concordancia y vigencia de la misma, sin perjuicio de la facultad del tribunal de disponer su presentación y/o su reserva si lo considera necesario).

En caso que la prueba sea pendrive, disco o soporte magnético: se ofrece y se pone a disposición. El Tribunal lo puede requerir en cualquier momento.

En relación a las audiencias de prueba: a) Reconocimiento: se corre traslado de la documentación en los términos del art. 243 del CPCC. b) Exhibición: se difiere para tomarse previo a elevar la causa a juicio o el tribunal le otorga un plazo para que la parte proceda a digitalizarla y adjuntarla en escrito electrónico (según el volumen). La documentación original puede ser requerida por el tribunal interviniente en cualquier momento.

Respecto a la prueba pericial: firme el decreto de prueba, se efectúan los sorteos a través del SAC Multifuero y se notifica a las partes. Las mismas pueden, en el plazo de tres días, hacer uso de la facultad conferida en el art. 264 del CPCC de proponer nuevos puntos de pericia.

El perito acepta el cargo y el Tribunal analiza en cada caso la factibilidad de realizar la pericia de manera inmediata o diferirla si no es posible realizarla sin desplazamiento de partes, auxiliares y operadores, realizando la pericia en lo posible con las constancias de autos o requiriendo a las partes la digitalización de la documental pertinente.

Para diligenciar la pericia médica, el perito puede: a) solicitar que la misma se difiera y no 
fijar fecha. b) fijar fecha con los recaudos de restricción de la circulación derivadas de la emergencia sanitaria lo permitan y dando cumplimiento a las recomendaciones del COE en relación a la prevención requerida (uso de tapaboca, y en caso de síntomas, avisar con anticipación para la postergación de la misma).

En relación a la pericia caligráfica, en la etapa de presencialidad administrada se fija fecha para la realización en la sede del Tribunal del cuerpo de escritura. Respecto a la pericial contable se pide al perito contador oficial que -de acuerdo a los puntos periciales- detalle la documentación necesaria para realizar la labor encomendada y dicha documental deber ser digitalizada e incorporada al SAC.

Asimismo para diligenciar la prueba informativa, mediante oficio electrónico, se sumaron nuevas entidades adheridas y debe tenerse en cuenta la posibilidad de pedir prórroga ante dificultad de diligenciamiento fundado.

Respecto al diligenciamiento de informativas en Afip se puede remitir mail y en la SRT se implementó la mesa de entradas virtual y la página web de la SRT, enviar todo tipo de documentación y el sistema otorga número de ingreso con el cual se va a tramitar. Contestado el traslado o vencido el plazo sin evacuarlo, se certifica y se dispone la apertura de la causa a prueba, lo que se notifica de manera electrónica. Diligenciada la prueba, se eleva para continuar el trámite procesal por ante la Sala de la Cámara del Trabajo que por turno corresponda ${ }^{19}$.

\section{II.4.D) Otras alternativas de acceso a la Justicia en la Emergencia Sanitaria}

Se cuenta con Centros de Acceso a Justicia en Córdoba que dependen del Ministerio de Justicia y Derechos Humanos de la Nación.

Llevan a cabo un trabajo interdisciplinario, brindan atención legal primaria integral, servicios mediación comunitarias, patrocinio jurídico gratuito, etc.

En el informe sobre el trabajo efectuado en la pandemia manifestaron que "el acceso a justicia de las personas más vulnerabilizadas por la desigualdad social es además un derecho humano inalienable que no admite demora".

Creemos que ello condice con el Programa de Naciones Unidas para el desarrollo de los objetivos de desarrollo sostenible ${ }^{20}$. El mismo es un llamado universal para poner fin a la pobreza, proteger el planeta y garantizar que todas las personas gocen de paz y prosperidad para 2030. Mediante la consecución de 17 objetivos.

Siendo el objetivo 16 el que tiene por finalidad promover sociedades pacíficas e inclusivas para el desarrollo sostenible, facilitar el acceso a la justicia para todos y crear instituciones eficaces, responsables e inclusivas a todos los niveles.

\section{Reforma procesal. Conclusiones}

-Celebramos los avances de la reforma procesal en general y en particular las facultades otorgadas al Juez de Conciliación y del Trabajo como director del proceso para intervenir,

19 KIATKOVSKI, Silvia, "Proceso laboral cordobés en tiempo de Covid 19. Normativa reglamentaria dictada por el TSJ con motivo de la emergencia sanitaria provocada por el Covid-19.Procedimiento ante el Juez de Conciliación”, exposición del 3/7/20.

20 PROGRAMA DE NACIONES UNIDAS PARA EL DESARROLLO. Ver https://www.undp.org/content/undp/es/home/sustainable-development-goals.html. 
dirigir y reconducir la prueba, lo cual en armonía con la la aplicación de los principios procesales de celeridad, inmediatez y oralidad se pueda agilizando la actividad probatoria.

- Para lograr resultados eficaces se debe capacitar al personal, con trabajo conjunto de las dependencias correspondientes, para readaptar la infraestructura y la realidad judicial en general para lograr los fines propuestos en la ley, mediante la aplicación progresiva en etapa previa o ensayo, con el apoyo de la Comisión de Seguimiento de la misma y de la Oficina de Mediación Judicial.

- Se debe profundizar el concepto de acceso a justicia y reforzar los mecanismos conciliatorios administrativos para evitar judicializar las controversias de menor cuantía y complejidad y /o acortar los tiempos de los procesos.

- Finalmente proponemos que todos los operadores jurídicos aunemos esfuerzos de estudios, propuestas y trabajos en aras de lograr en el momento que la necesaria reforma procesal sea aplicada, para lograr el mejor resultado de la misma y así procurar en forma integral que la justicia social sea lograda para el justiciable.

\section{Reflexiones y propuestas. Emergencia Sanitaria.}

A partir de la emergencia sanitaria, la actividad judicial se vio resentida, desarrollándose mecanismos técnicos, procesales y tecnológicos que posibilitaron llevar a cabo progresivamente los actos procesales.

Las crisis conllevan oportunidades para reformular opciones que permitan obtener resultados positivos.

Las acciones actitudinales implican no alarmarse y estar preparados en todo momento para hacer frente a cualquier emergencia, actuar con seguridad y precisión (aunque lo resuelto pueda hacerse de otro modo o perfeccionarse).

Las acciones cognoscitivas y aptitudinales se construyen profundizando conocimientos e interés de reconducir la emergencia sanitaria utilizando los mecanismos procesales y tecnológicos en forma proactiva, otorgando soluciones prácticas y sencillas, para lograr que el derecho del trabajo y el derecho procesal del trabajo sean inclusivos, integrales y protectorios, facilitando el acceso a justicia, la igualdad de derechos y a la vez garanticen el debido proceso. 


\section{Referencias Bibliográficas}

- Altamira Gigena Raúl E., "Ley de Contrato de Trabajo. Comentada y Concordada”, Editorial Errepar, Buenos Aires, 2010.

-Arese, César, "La necesidad de reformas laborales", Ponencia ante el II Seminario Internacional de Derecho del Trabajo, San Marcos Sierras, Córdoba, 23 y 24 de marzo de 2018, organizado por la Asociación Argentina de Derecho del Trabajo y la Seguridad Social Noroeste.

- Arese César, “Derechos Humanos Laborales.Teoría y Práctica de un nuevo derecho del trabajo", Editorial Rubinzal - Culzoni, 2014, Santa Fe.

- Arese César, director, Ricardo León Chércoles y María de los Ángeles Ferrario, coordinadores, "Nuevas Tecnologías.Presente y Futuro del Derecho del Trabajo", Editorial Rubinzal -Culzoni, Santa Fe, 30/8/19.

- Asociación de Magistrados y Funcionarios Judiciales - Instituto de Estudios de la Magistratura, "Jornadas de Debate sobre el Proyecto de Reforma de la ley 7987 Juicio Abreviado y Sumarísimo", 6 y 7 de abril de 2018.

- Babio, Alejandro Oscar, "Teoría y técnica probatoria en el proceso laboral", Librería Editora Platense, La Plata 1998.

- Bosio, Rosa Elena, “Lineamientos Básicos del Derecho Social. Tomo II”, Editorial Advocatus, Córdoba, 2019.

- Brain, Daniel Horacio, "Derecho Procesal del Trabajo", Editorial Advocatus, Córdoba 2008.

- Calvimonte, Beatriz- Lascano, Eduardo J., "Derecho del Trabajo. Interpretación Judicial. Jurisprudencia. Sala Laboral TSJ 2005 - 2018", Editorial Advocatus, mayo de 2019.

- Chercoles Ricardo- Ferrario María de los Ángeles," El impacto de las transformaciones tecnológicas y el futuro del Derecho del Trabajo en América Latina, con especial referencia a los "trabajadores vulnerables", en "Nuevas Tecnologías.Presente y Futuro del Derecho del Trabajo", Editorial Rubinzal -Culzoni, Santa Fe, 30/8/19.

- Chercoles, Ricardo, "Conferencia El futuro es hoy. El impacto de las transformaciones tecnológicas en el Derecho del Trabajo", Zoom, 24/6/20.

- Chercoles, Ricardo, "Renovación de los indicadores de laboralidad, a raíz de las formas atípicas de trabajo",2019.

- Costa magna, Alivio - Luque Mariño, Fernando, Proyecto de Código Procesal Laboral de San Luis. Propuesta", 2015.

- Costamagna Olivio, Verónica Varela López, Graciela López Priori, “Pandemia COVID-19

- Consecuencias económicas, sociales y laborales en la República Argentina".

- Echenique, Marcelo, "Análisis del Proyecto de Ley de reforma al Código de Procedimiento Laboral de la Provincia de Córdoba (Ley 7987)", 2018.

- Ferreyra de De la Rúa Angelina - Rodríguez Juárez, Manuel (directores), “Tribunal Superior de Justicia de Córdoba. Máximos Precedentes", autoras; Guevara, Carina NoemíMartínez, María Soledad, "Precisiones en torno a los principios de gratuidad y de igualdad de trato y no discriminación en el Derecho del Trabajo", Editorial La Ley, Buenos Aires, 2013.

-García Vior Andrea, "El futuro es hoy", Conferencia sobre Teletrabajo. Su incidencia en las cuestiones de género. Zoom, 24/6/20

- Giletta, Ricardo, Díaz, Silvia y El Hay, Nancy, “Anexo Código Procesal Laboral de la Provincia de Córdoba", 2018.

-Guevara, Carina Noemí - Medrano Ortiz, Ivonne, “Estatutos Especiales y Temas Procesales Actuales", Seco, Ricardo (director), "Audiencia de Conciliación. Aportes para lograr la conciliación de la causa", Cuadernos del Instituto de Derecho del Trabajo y de la Seguri- 
dad Social, SJ Volumen 60, "P. Alberto Hurtado", Editorial Advocatus, julio de 2013.

- Guevara, Carina Noemí, "Análisis de los principales Aspectos de la Conciliación y la Prueba en la Reforma a la Ley Procesal del Trabajo de Córdoba", en Revista de Estudio de Derecho Laboral y Derecho Procesal Laboral, Sala de Derecho Laboral y Derecho Procesal Laboral, Instituto de Investigación en Ciencias Jurídicas Universidad Blas Pascal, p.53, Córdoba, Argentina, Año 1, Nro. 1, noviembre 2019 // ISSN Versión online: XXXX-XXXX.

- Guevara, Carina Noemí Tema: " Aspectos fundamentales y problemáticos del proceso laboral cordobés en tiempos de COVID 19", Consideraciones Prácticas y Jurídicas.Actuación Asesoría Letrada del Trabajo. Organizado por grupo Derecho Laboral Argentino y Federación del Colegio de Abogados de la Provincia de Córdoba,3/7/20.

- Highton de Nolasco, Elena, Conferencia: "Los jueces estamos para garantizar el acceso a justicia" del 14/6/10. https://www.cij.gov.ar/nota-4501-Highton---Los-jueces-estamospara-garantizar-acceso-a-justicia-.html//https://www.cij.gov.ar/nota-32632-Highton-present--nuevos-proyectos-de-acceso-a-justicia.html.

- Kiatkovski, Silvia, "Actividad del fuero laboral de la Provincia de Córdoba durante el aislamiento social preventivo y obligatorio", en Espacio para compartir novedades en materia laboral, Derecho Laboral Argentino, autor Ab. Esp. Hernán Piazza.

http://dtyss.blogspot.com/2020/06/actividad-del-fuero-laboral-cordobes.html?m=1, 23/6/20.

- Kiatkovski Silvia, "Proceso laboral cordobés en tiempo de Covid 19. Normativa reglamentaria dictada por el TSJ con motivo de la emergencia sanitaria provocada por el Covid-19. Procedimiento ante el Juez de Conciliación, 3/7/20.

-Lozano Bosch, Mirna, "Dictamen que pretende regular el teletrabajo", entrevista radial con Ricardo Césari del 23/6/20.

- Martorell, Ernesto Eduardo, “Covid -19 (Coronavirus y Empresa), Problemática Laboral, Societaria y Concursal, Editorial Rubinzal -Culzoni, Editores, Santa Fe, 10/6/20.

- Ministerio de Justicia y Derechos Humanos de la Nación, Dirección Nacional de Promoción y Fortalecimiento para el Acceso a la Justicia. Informe de actividades en A.S.P.O., 2020.

- Moreno del Papa, Duilio, “Cuarentena. Aislamiento Social Obligatorio: Marco Normativo en Argentina y la legalidad de sus disposiciones", junio/20.

- Palacio de Caeiro, Silvia B. (directora), "Tratados de Derechos Humanos y su influencia en el Derecho Argentino", Editorial La Ley, 2015, Bs.As.

-Proyecto de Ley de Reforma Procesal de la Provincia de Bs. As, 2018.

- Sappia, Jorge, Giletta, Ricardo y Salomón, Marcelo, $4^{\circ}$ Encuentro - La reforma procesal laboral: Perspectivas y desafíos (24/04/2019). - Ley 10.596", dictada durante el mes de abril 2019 por el IEM y el Centro Núñez.

- Seco, Ricardo Francisco, "El proyecto de reforma procesal en la Provincia de Córdoba", XXII Congreso Nacional de Derecho del Trabajo y de la Seguridad Social, 4 y 5 de octubre de 2018, Santa Fe. Módulo Reformas Procesales en los ámbitos provinciales y en la Ciudad Autónoma de Buenos Aires.

- Seco, Ricardo Francisco (director), ¿Es obligatorio el seguimiento de los fallos de la CSJN?, investigación UBP, año 2018.

- Seco, Ricardo Francisco (director), "Ley Procesal del Trabajo de la Provincia de Córdoba", Editorial Advocatus, 2008.

- Toselli Carlos y Ulla, Alicia G., “Código Procesal del Trabajo”, Ediciones Alveroni, 2da edición ampliada y actualizada, 2007. 